\title{
Antifungal activity of microcapsule propolis from Tetragonula spp. to Candida albicans
}

\author{
Diah Kartika Pratami ${ }^{\mathrm{a}}$, Teti Indrawati ${ }^{\mathrm{b}}$, Iis Istikomah ${ }^{\mathrm{b}}$, Siti Faridac $^{\mathrm{c}}$, Paksi Pujiantod, Muhamad \\ Sahlan ${ }^{\mathrm{d}, \mathrm{e}^{*}}$
}

${ }^{a}$ Lab of Pharmacognosy and Phytochemistry, Faculty of Pharmacy, Pancasila University, South Jakarta, 12640, Indonesia

${ }^{b}$ Faculty of Pharmacy, National Institute of Science and Technology (ISTN), South Jakarta, 12640, Indonesia

${ }^{c}$ Department of Medical Pharmacy, Faculty of Medicine, Jakarta, 10430, Indonesia

${ }^{d}$ Department of Chemical Engineering, Faculty of Engineering, Depok, 16424, Universitas Indonesia

${ }^{e}$ Research Center for Biomedical Engineering, Faculty of Engineering, Depok, 16424, Universitas Indonesia

Received: 15 May 2020 / Received in revised form: 29 May 2020 / Accepted: 31 May 2020

\begin{abstract}
Propolis is a mixture of resin and saliva of Tetragonula spp. that have an antifungal activity. The purpose of this study was to develop spraydried microcapsule propolis (SDMP) and to analyze its antifungal activity to Candida albicans. The SDMP was obtained using maltodextrin and gum Arabic coating with a spray drying method. The antifungal activity of SDMP of rough propolis (taken from the outside beehive) and smooth propolis (taken from the inside beehive) was analyzed. The macroscopic characterization showed that SDMP had a brownish-yellow powder form and a spherical uniform particle with the size of $9.32-14.61 \mu \mathrm{m}$. The encapsulation efficiency of SDMP of smooth and rough type was $81.22 \%$ and $83.04 \%$; moisture content of $5.58 \%$ and $5.84 \%$; water solubility of $98.19 \%$ and $98.31 \%$, respectively. The diameter of microbial inhibitory to $C$. albicans was in the range of $6.33 \pm 1.5$ to $10 \pm 2.5 \mathrm{~mm}$. SDMP displayed remarkable activity in the assays against $C$. albicans.
\end{abstract}

\section{Introduction}

Candidiasis is one of the most common fungal infections which are caused by Candida $s p$. Candidiasis infection is one of the existing diseases in Indonesia ranging from superficial (oral cavity, esophagus, intestine, vagina, and other epidermal and mucosal surfaces) to deep infection (brain, eye, kidney, liver, heart, and other major organ tissues) [1]. Here propolis is known to have antifungal properties to Candida $s p$ [1].

Propolis is a mixture of resin and bee saliva collected by honeybees from plant buds, leaves, and stems with various physical properties [2]. It has various chemical constituents affected by location, vegetation, and time [3] with the main ingredients of flavonoids, tannins, and phenolic acids [4]. Indonesian propolis genereally has a number of pharmacological properties as the antioxidant, antiinflammatory, antibacterial, anticancer, anti-angiogenic, xanthine oxidase inhibitory, and antifungal [5-9].

Observations performed by Sahlan reported the ability of ethanol extract of Indonesian propolis (EEP) to inhibit the growth of Candida albicans. Thus, propolis is potential to be developed into a pharmaceutical preparation for treating candidiasis [9]. Indonesian propolis was tested with LC-

* Corresponding author. Tel.: +62-21-7863516; fax: +62-21-7863515. Email: sahlan@che.ui.ac.id
MS/MS methods, which resulted in the founding of three anti candidiasis compounds: adhyperforin, kurarinone, and deoxypodophyllotoxin [9]. The chemical compounds contained in Indonesian propolis differ from other propolis in accordance with its vegetation source; the bee that produces it, and its geographic origin environment, also differentiating its antifungal potential.

However, the application of propolis in the manufacture of pharmaceutical preparations is still limited in view of some characteristic properties of propolis including its low solubility in water, having sticky thick liquid, gummy, and blackish-brown form with strong taste and aroma [10]. Propolis microencapsulation using the spray drying method could be employed to overcome propolis handling properties' problematic obstacles. The microencapsulation with spray drying is not only low cost but also effective method to turn suspensions into the powdered microparticles, which comprise one or more wall materials and a core. The microencapsulation process protects the bioactive compounds from any adverse environmental conditions [8].

The purpose of this study was to develop spray-dried microcapsule propolis (SDMP) and to analyze its antifungal activity to Candida albicans. The determination of Indonesian propolis, specifically from Tetragonula spp. bee as an antifungal agent, revealed its ability as candidiasis drug. 


\section{Materials and Methods}

\subsection{Samples}

Ethanol extract propolis (EEP) was obtained from the RIN Biotek Indonesia Company. It was taken from North Luwu South Sulawesi. There were two types of propolis: rough propolis (taken from the outside beehive) and smooth propolis (taken from the inside beehive).

\subsection{Microencapsulation of Propolis by Spray Drying}

Rough and smooth EEP was extracted from Tetragonula spp beehive with a method as described by Sahlan et al. [11]. The encapsulant material was prepared from maltodextrin (MD) and gum arabic (GA) 10:1 as described by DK Pratami et al. [12]. Maltodextrin DE 18 (dextrose equivalent) and gum arabic were purchased from Bratachem Co. (Jakarta, Indonesia). The ratio between the coating material and EEP was 1:1. The coating material solution was prepared by stirring $10 \mathrm{~g}$ of MD, $1.0 \mathrm{~g}$ of GA in $100 \mathrm{~mL}$ of distilled water at $6000 \mathrm{rpm}$ for 30 minutes. Then the coating material solution was homogenized by an Ultra-Turrax T18 (IKA, Königswinter, Germany) for two minutes at $15000 \mathrm{rpm}$. Then, the $300 \mathrm{ml}$ of EEP (37.067 mg/mL solids) was added gradually and homogenized in the Ultra-Turrax T18 fortwo minutes more. The mini spray dryer (Büchi B290, Flawil, Switzerland) was employed to the obtained SDMP. The operational conditions of the spray dryer included nozzle diameter of $1.5 \mathrm{~mm}$; aspirator $100 \%$; flow rate at $8 \mathrm{~mL} / \mathrm{min}$; spray gas of $600 \mathrm{~L} / \mathrm{min}$, inlet temperature at $110^{\circ} \mathrm{C}$; and outlet temperatures between $65^{\circ} \mathrm{C}$ and $73^{\circ} \mathrm{C}$.

\subsection{Physical Characterization of SDMP}

One gram of each SDMP sample was determined for the moisture content (MC) measurement by moisture balance analyzer AMB (Adam, USA) at the temperature of $105^{\circ} \mathrm{C}$. The solubility of SMDP in water was determined based upon the gravimetric analysis method. For that, one gram of SDMP was added in $100 \mathrm{~mL}$ distilled water under magnetic stirring for 5 minutes. The solution was filtered through a filter paper weighed on an analytical balance before used. After filtration, filter paper and residue were dried in the oven for 1 hour at the temperature of $105{ }^{\circ} \mathrm{C}$. The solubility of SDMP in water (\%) was calculated by using the following Eq. (1).

$$
\% \text { Solubility }=\left[1-\left(\frac{P_{c}-P_{b}}{\frac{100-\% M C \times P_{a}}{100}}\right)\right] \times 100 \%
$$

where $\mathrm{Pc}(\mathrm{g})$ refers to the weight of the filter paper plus residue after dried; $\mathrm{Pb}(\mathrm{g})$ is the weight of the filter paper weighed before used; $\mathrm{Pa}(\mathrm{g})$ is the weight of the SDMP; and MC (\%) is the moisture content of the SDMP.

The morphology of SDMP was observed by scanning electron microscope (JSM6400; JEOL, Tokyo, Japan) at the Fire and Safety Engineering Laboratory, Faculty of Engineering, State Jakarta University. SEM analyses were performed at room temperature, and all samples were coated with a layer of gold in a vacuum before observing microscopy. The size of SDMP was determined by Beckman Coulter Delsa Nano Particle Size Analyzer (PSA) in Physics Research Institute LIPI, Serpong.

\subsection{Chemical Characterization of SDMP}

The chemical quantification of SDMP was determined as total phenolic content (TPC) and total flavonoid content (TFC) described by Diva et al. with modification [13]. FolinCiocalteau method with gallic acid as its standard was used to estimate the TPC. Total phenolic levels were estimated by measuring gallic acid and described in $\mathrm{mg}$ GAE/g extract content. This method was based on the color change of FolinCiocalteau reagent that was reduced by sodium carbonate in the presence of phenolic substances. The absorbances of gallic acid with concentrations of 0 to $300 \mu \mathrm{g} / \mathrm{mL}$ were used to create the standard calibration curve. $50 \mathrm{mg}$ of SDMP was weighed and dissolved in methanol to $200 \mu \mathrm{g} / \mathrm{mL}$ concentration, where this content was stirred using a vortex for 5 minutes. Then, a $5 \mathrm{~mL}$ Folin-Ciocalteau reagent and 0.5 $\mathrm{mL}$ of diluted samples were mixed in a tube. After leaving the tube in a dark environment for 5 minutes, $4 \mathrm{~mL}$ sodium carbonate solution was added into the tube. The absorbance was measured with spectrophotometer UV-Vis at $745 \mathrm{~nm}$ only after 15 minutes of reaction time in a dark room.

The determination of TFC was carried out using the $\mathrm{AlCl}_{3}$ method with quercetin as its standard. Total flavonoids levels were estimated by measuring quercetin and described in $\mathrm{mg}$ $\mathrm{QE} / \mathrm{g}$ extract content. The absorbances of quercetin with the concentrations 0 to $200 \mu \mathrm{g} / \mathrm{mL}$ were used to create the regression linear calibration. The $50 \mathrm{mg}$ SDMP was made diluted with methanol to a concentration of $200 \mu \mathrm{g} / \mathrm{mL}$. The sample solution was taken $0.5 \mathrm{~mL}$ into the test tube, and then was added with $1.5 \mathrm{~mL}$ of methanol, $0.1 \mathrm{~mL}$ of $10 \% \mathrm{AlCl}_{3}$ solution, $2.8 \mathrm{~mL}$ aquadest, and $0.1 \mathrm{~mL} \mathrm{KCH}_{3} \mathrm{COO} 1 \mathrm{M}$. The result of the mixture was vortexed and let standing for 30 minutes. The absorbance subsequently was measured at $\lambda 415$ $\mathrm{nm}$ with spectrophotometer UV-Vis.

\subsection{Microencapsulation Yields (MY) and Efficiency (ME)}

The MY was determinated by calculating the mass lost during the spray drying process. The MY (\%) was calculated as the ratio of the SDMP collected after the spray drying experiment to the total initial amount of EEP and encapsulant. The MY (\%) was calculated using Eq. (2).

$$
\text { MY }=\frac{\text { Mass of the SDMP after drying }}{\text { Theoretical Mass }} 100
$$

The microencapsulation efficiency (ME) was performed to determine the ability of maltodextrins - gum arab coating of active compounds from propolis extract. The ME (\%) process was calculated based on Eq. (3).

$$
M E=\frac{A-B}{A} \times 100
$$


where, $\mathrm{A}$ is the total phenolics added initially to the solution entering the spray dryer ( $\mathrm{mg} \mathrm{GAE} / \mathrm{g}$ ) and $\mathrm{B}$ is the total phenolics unencapsulated in the SDMP (mg GAE/g).

\subsection{Fourier Transform Infrared Spectroscopy (FTIR)}

The sample was SDMP, propolis powder without encapsulation, and the encapsulant (maltodextrin - arabic gum). Samples were dropped onto a thin layer of $\mathrm{KBr}$ for 1 drop, and characterized using an FTIR analyzer Shimadzu IR Prestige21/FTIR-8400S. FTIR spectra were read on infrared waves from 4000 to $500 \mathrm{~cm}^{-1}$. Tests were carried out at the Laboratory of the Department of Chemical Engineering, Universitas Indonesia.

\subsection{Antifungal Assays}

The stock ATCC culture $C$. albicans was obtained from the Department of Parasitology, Faculty of Medicine, Universitas Indonesia. The stock culture used was in a minimum age of 48 hours. The test was done with the disc diffusion method as described by Silici et al. and Pereira et al. with slight modifications $[14,15]$. The diffusion method using paper discs with a diameter of $6 \mathrm{~mm}$. All tools, before being used were sterilized in the autoclave for 15 minutes at $121^{\circ} \mathrm{C}$. The $C$. albicans inoculum was prepared to the Muller Hinton medium for later inoculation in the petri dish. The preparation was done to obtain McFarland 0.5 standard turbidity equal to the concentration of $1.5 \times 10^{8} / \mathrm{ml}$ cell density. The prepared $C$. albicans colonies were then transferred using the counter strike method to its medium. Paper discs that have been immersed in a sample solution for 3 minutes were placed on the surface of the agar media that has been inoculated with the test fungus using sterile tweezers, and then incubated for 48 hour at room temperature in a reverse manner. Fluconazole and nystatin were used as a positive control. Blank discs were later soaked in SDMP at 3 different concentrations: 1; 3; and $5 \%(\% \mathrm{w} / \mathrm{v})$ before being used. After 48 hours of incubation at room temperature, the diameter of microbial inhibition was measured using a vernier caliper.

\section{Results and Discussion}

\subsection{The Physical Characterization of SDMP}

In this research, the SDMP was obtained by the spray drying process using maltodextrin-arabic gum as an encapsulant. The liquid EEP could conserve into a powder with a very homogenous small size. The macroscopic of SDMP was in the form of a brownish-yellow powder with a distinctive smell of propolis, and bitter taste (Fig. 1).

The MY of spray-dried EEP without microencapsulation (Fig. 1a) was only $22 \%$ indicating $78 \%$ lost during the spray dry process, and stuck to the spray drying chamber glassware. The SDMP from rough and smooth propolis type is shown in Fig. 1c and Fig. 1d. MY value was $67.27 \pm 6.75 \%$ and $67.72 \%$ $\pm 6.75 \%$, respectively. From the MY value, it can be seen that microencapsulation could improve the yield of the spray drying process. The MY of SDMP microcapsules had a good value. It valued higher than SDMP as obtained by
Marquiafável et al. using gum Arabic - silicon dioxide (1:1) encapsulant, resulted in MY between 31.85 and 67.60\% [16].

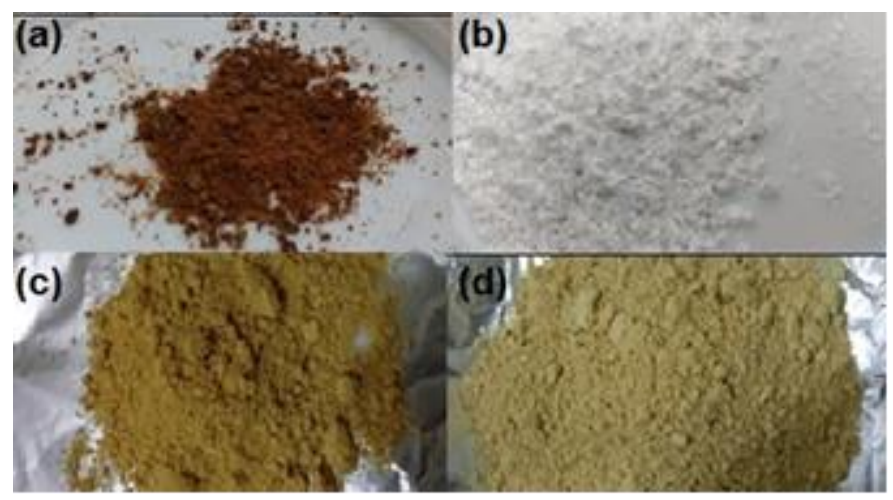

Fig.1. Spray drying powder results: (a) Propolis without encapsulation; (b) maltodextrin-gum Arabic; (c) SDMP rough type; and (d) SDMP smooth type

In this research, as shown in Table 1 the moisture content of SDMP for both smooth and rough type was $5.84 \%$ and $5.58 \%$ the water solubility was $98.19 \%$ and $98.31 \%$, respectively.

Table 1. The characterization of SDMP

\begin{tabular}{lccc}
\hline Parameters & $\begin{array}{c}\text { Spray-dried } \\
\text { EEP without } \\
\text { encapsulation }\end{array}$ & $\begin{array}{c}\text { SDMP smooth } \\
\text { type }\end{array}$ & $\begin{array}{c}\text { SDMP } \\
\text { rough type }\end{array}$ \\
\hline MY $(\%)$ & $22.00 \pm 6.75$ & $67.72 \% \pm 6.75$ & $67.27 \pm 6.75$ \\
Moisture content $(\%)$ & $2.04 \pm 6.75$ & $5.84 \pm 0.01$ & $5.58 \pm 0.05$ \\
Water solubility $(\%)$ & $74.01 \pm 0.02$ & $98.19 \pm 0.02$ & $98.31 \pm 0.02$ \\
Particle size $(\mu \mathrm{m})$ & - & $9.32 \mu \mathrm{m}$ & $14.61 \mu \mathrm{m}$ \\
\hline
\end{tabular}

Note: The data was given in mean $+\mathrm{SD}, \mathrm{n}=3$ experiment. EEP, ethanolic extract propolis, MY, microencapsulation yield; and SDMP, spray drying microcapsule propolis

The results of this study showed that the solubility of SDMP in the water was affected by maltodextrin in which when more maltodextrins were added, the solubility of propolis powders was higher and the content of moisture came to be lower [12]. Maltodextrin successfully increased the solubility and decreased the moisture content of propolis. The problem of low solubility in water was solved by microencapsulation. Some studies have explored the use of maltodextrin with dextrose equivalent (DE) value ranging from 10 to 20 to protect bioactive compounds, such as phenolic compounds [8]. The microencapsulation using the spray drying method could be employed to overcome propolis handling properties' problematic obstacles.

The microencapsulation could increase the value of solubility in water, the moisture content, and MY. The higher encapsulant concentration in the SDMP could increase the percentage of moisture content, water solubility, and MY [12]. The moisture content of SDMP was below $10 \%$, the maximal limitation of powder moisture content. The measurement of moisture content below $10 \%$ indicated the high percentage of the core material and encapsulant in spray-dried powder. The minimal moisture content value could prevent decompositiondue to chemical degradation or microbial 
contamination [17]. The EEP without encapsulated had lower moisture content compared to the SDMP, due to its lipophilic characteristic. The maltodextrin encapsulant had a hygroscopic characteristic that increased the moisture content value.

Table 1 shows the results of the particle size distribution of SDMP. The particle size on SDMP was influenced by the size of the spray drying nozzle, the thickness of the polymer solution, the dispersion of active substances in polymer solutions, and surface tension.

Fig. 2 shows the micrographs of SDMP. The micrographic of unencapsulated smooth and rough EEP powder as shown in Fig. 2a-b presented the agglomerate particles with heterogeneous shape, uneven surface, and the diameter of 3 to $9 \mu \mathrm{m}$. The SEM micrographs of unencapsulated EEP presented in this research were similar to the propolis microscopic analysis as identified by Machado et al. [18]. The micrographics of smooth and rough SDMP shown in Fig. 2c-d presented homogenous spherical particles. The SEM micrographs of SDMP showed the visualization similar as observed by Busch et al. [10]. The micrographic of MD-GA powder as depicted in Fig. 2e as empty encapsulant without any core material inside presented curved surface and vacuole in its core. The spray drying microencapsulation improved the size uniformity and integrity, and showed the better protection of core material microparticles.
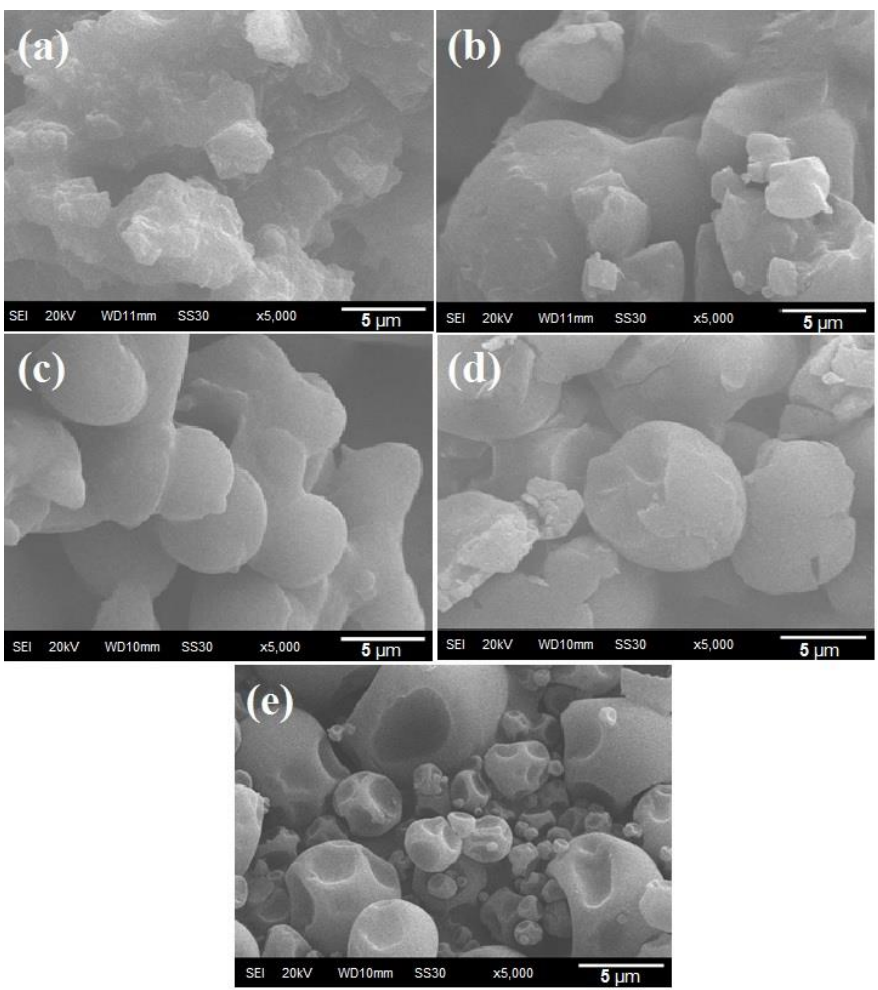

Fig.2. SEM image: (a) Unencapsulated smooth EEP; (b) Unencapsulated rough EEP; (c) SDMP smooth type; (d) SDMP rough type; and (e) MD-GA

\subsection{Chemical Characterization of SDMP}

Table 2 shows the value of TPC and TFC. Based on a standard curve of gallic acid, we obtained the equation of line $\mathrm{y}=0.0052 \mathrm{x}+0.1861$ and $\mathrm{R}^{2}=0.99113$ where $(\mathrm{Y})$ refers to absorbance and $(\mathrm{X})$ is concentration. The TPC value in this research was higher than that of research by Marquiafável et al. that achieved TPC of propolis microcapsules in the range of 42.693 to $50.740 \mathrm{mg} \mathrm{GAE} /$ gram [16].

In measuring the total flavonoids, quercetin standard was made as a comparison. The value of the total flavonoid content in the sample could be measured from the standard quercetin calibration equation obtained, namely $\mathrm{Y}=0.0067 \mathrm{x}$ 0.0082 , with the relation coefficient value $\left(\mathrm{R}^{2}\right)=0.99861$.

The EEP smooth type contained a higher TPC and TFC value compared to the rough type. In this case, EEP smooth type, originating from inside the hive, was higher in TPC and TFC than the EEP rough one, originating from outside the hive [9]. Indonesian propolis from Tetragonula spp. bee has a TPC and TFC value higher than Malaysian propolis as reported by Rosli et al. [19] in which the TPC value is in the range of $9.1 \pm 0.10 \mu \mathrm{g} \mathrm{GAE} / \mathrm{mL}$ to $56.9 \pm 0.12 \mu \mathrm{g} \mathrm{GAE} / \mathrm{mL}$ and the TFC value is in the range of $61.5 \pm 0.15 \mathrm{mg} \mathrm{QE} / \mathrm{mL}$ to $163.9 \pm 0.10 \mathrm{mg} \mathrm{QE} / \mathrm{mL}$. Meanwhile, the TFC of Indonesian propolis is higher compared to Taiwanese, Brazil, and China propolis in powdery products varied from $2.97 \pm 0.05 \%$ to $22.73 \pm 0.72 \%$ [20]. The chemical quantification of propolis even from the same beehive can have different characteristics, content, and properties. The value chemical content in propolis has a difference from its vegetation source, geographic origin, and bee species [21].

The ME of spray drying microencapsulation was determined by comparing the TPC or TFC of SDMP value between theoretical TPCs added initially to the solution before entering the spray dryer. The ME of TPC was found higher than that of TFC. Thus, the ME of SDMP was described as the efficiency of microencapsulation to encapsulate the TPC inside wall material. The ME value of SDMP smooth and rough type was $96.53 \%$ and $69.40 \%$. The ME value as shown in this study was close to Da Silva et al., obtaining the ME of propolis microparticles $85.1 \pm 0.9 \%$ [17], Rabia et al. who obtained ME of propolis microencapsulated using complex coacervation $98.77 \%$ [22]. A good ME was obtained when the maximum amount of core material was encapsulated inside the encapsulant particles. The ME value was influenced by the spray drying speed and the formation of microcapsules. The TPC of SDMP might increase if the speed was good and fast $[23,24]$.

Table 2. TPC and TFC of EEP and SDMP

\begin{tabular}{lcc}
\hline Sample & $\begin{array}{l}\text { TPC (mg GAE/ } \\
\text { g extract) }\end{array}$ & $\begin{array}{c}\text { TFC (mg QE/g } \\
\text { extract) }\end{array}$ \\
\hline EEP rough type & $857.8 \pm 3.34$ & $198.93 \pm 9.52$ \\
EEP smooth type & $970.67 \pm 6.67$ & $241.56 \pm 4.27$ \\
SDMP rough type & $786.03 \pm 9.52$ & $142.53 \pm 3.72$ \\
SDMP smooth type & $744.3 \pm 9.60$ & $71.4 \pm 7.08$ \\
\hline
\end{tabular}

Note: SDMP, spray drying microcapsule propolis; TPC, total phenolic content; TFC, total flavonoid content; GAE, gallic acid equivalents; and $\mathrm{QE}$, quercetin equivalents

\subsection{The FTIR Analysis}

As shown in Table 3 the SDMP had the functional group $\mathrm{O}-\mathrm{H}$ bonds, $\mathrm{C}=\mathrm{O}$ ester compounds, and $\mathrm{C}-\mathrm{H}$ compounds. In 
the spectra of EEP and encapsulant MD-GA, there was no structural change in SDMP. The spectra of propolis and maltodextrin - gum Arabic as the coating material was maintained after the spray dry process, according to Pratami et al., there may be no chemical reaction between the compounds in propolis with arabic gum - maltodextrin [7].

Table 3. FTIR Spectra Result

\begin{tabular}{cccc}
\hline Functional Group & EEP & SDMP & $\begin{array}{c}\text { Encapsulant } \\
\text { MD-GA }\end{array}$ \\
\hline O-H & $3308-3450$ & $3303-3345$ & $3296-3345$ \\
C-H & $2930-2936$ & $2929-2936$ & $2920-2936$ \\
C=O & $1694-1647$ & $1694-1647$ & 1647 \\
C-O & $1010-1150$ & $1010-1005$ & $1150-1076$ \\
\hline
\end{tabular}

\subsection{Antifungal Test}

The result of the antifungal test was described as the diameter of microbial inhibition (DMI). Table 4 shows the DMI of SDMP rough and smooth type. The DMI value of the SDMP rough type higher than that of the smooth type. According to the value of DMI, SDMP rough type 3\% and smooth type $5 \%$ had low sensitivity: while SDMP rough type $5 \%$ had medium sensitivity [25].

From all the data above, it can be stated that the difference of SDMP concentration at $1 \%, 3 \%$, and $5 \%$ of both smooth and rough types did not affect the inhibition ability of Candida albicans. It might be due to the concentration of SDMP itself was not different. It may be that none of the SDMP concentration was the most effective concentration, thus further research is needed to know the most optimum DMI. When compared between SDMP on most Candida albicans rough propolis was found to have a higher diameter of microbial inhibition than smooth type. The rough type, originating from outside the beehive, was higher in DMI than the smooth type, originating from outside the beehive. It was because the bee colony protected the outside nest more from microbial attack than the inside.

Table 4. The diameter of microbial inhibitory of SDMP

\begin{tabular}{lcc}
\hline Sample & $\begin{array}{c}\text { SDMP rough } \\
\text { type }(\mathrm{mm})\end{array}$ & $\begin{array}{c}\text { SDMP smooth } \\
\text { type }(\mathrm{mm})\end{array}$ \\
\hline $1 \%$ & $4.33 \pm 2.5$ & $3.33 \pm 1.5$ \\
$3 \%$ & $6.68 \pm 1.1$ & $5.33 \pm 1.5$ \\
$5 \%$ & $9.67 \pm 0.5$ & $7.33 \pm 1.7$ \\
Flu $(\mathrm{K}+)$ & $35 \pm 1$ & $33.67 \pm 2.3$ \\
Nys $(\mathrm{K}+)$ & $21 \pm 2.6$ & $19 \pm 1.7$ \\
K (-) & 0 & 0
\end{tabular}

Note: K(+), Control positive; Flu, Fluconazol; Nys, Nystatin; K (-), Control negative (Aquadest steril)

\section{Conclusion}

Propolis microencapsulation using the spray drying method could be employed to overcome propolis handling properties' problematic obstacles. The application of propolis in the manufacture of pharmaceutical, cosmetic, traditional medicine, and food supplement preparations could be done. Propolis has antifungal potency to inhibit the growth of Candida albicans. The rough type, originating from outside the beehive, was found higher in DMI compared to the smooth type, originating from outside the beehive.

\section{Acknowledgments}

The author gratefully acknowledges the financial support from the Ministry of Research and Technology / National Agency for Research and Innovation, the Republic of Indonesia through PTUPT Grant 2020 No: NKB321/UN2.RST/HKP.05.00/202; addendum No: NKB2920/UN2.RST/HKP.05.00/2020.

\section{References}

1. M. Sahlan, D. K. Mandala, D. K. Pratami, R. Adawiyah, A. Wijarnako, K. Lischer, et. al., Exploration of the antifungal potential of Indonesian propolis from Tetragonula biroi bee on Candida sp. and Cryptococcus neoformans, Evergr. J. 7 (2020) 118-125.

2. V. Bankova, S. De Castro, M. Marcucci, Propolis : Recent advances in chemistry and plant origin, Apidologie. 31 (2000) 3-15.

3. M. A. Savka, L. Dailey, M. Popova, R. Mihaylova, B. Merritt, M. Masek, et al., Chemical composition and disruption of quorum sensing signaling in geographically diverse United States propolis, Evidence-Based Complement, Altern. Med. 2015 (2015).

4. U. Czyzewska, J. Kononczuk, J. Teul, P. Dragowski, R. Pawlak-Morka, A. Surazynski, et. al., Verification of chemical composition of commercially available propolis extracts by gas chromatography-mass spectrometry analysis, J. Med. Food. 18 (2015) 584-591.

5. S. Farida, M. Sahlan, E. Rohmatin, R. Adawiyah, The beneficial effect of Indonesian propolis wax from Tetragonula sp. as a therapy in limited vaginal candidiasis patients, Saudi J. Biol. Sci. (2019) 0-4.

6. M. Iqbal, T. Fan, D. Watson, S. Alenezi, K. Saleh, M. Sahlan, Preliminary studies: The potential anti-angiogenic activities of two Sulawesi Island (Indonesia) propolis and their chemical characterization, Heliyon. 5 (2019) e01978.

7. R. Miyata, M. Sahlan, Y. Ishikawa, H. Hashimoto, S. Honda, S. Kumazawa, Propolis components from Stingless bees collected on South Sulawesi, Indonesia, and their xanthine oxidase inhibitory activity, J. Nat. Prod. 82 (2019) 205-210.

8. D. K. Pratami, A. Mun, A. Sundowo, M. Sahlan, Phytochemical profile and antioxidant activity of propolis ethanolic extract from Tetragonula bee, Pharmacogn. J. 10 (2018) 73-80.

9. M. Sahlan, A. Devina, D. K. Pratami, H. Situmorang, S. Farida, A. Munim, B. Kusumoputro, M. Yohda, A. Faried, M. Gozan, Antiinflammatory activity of Tetragronula species from Indonesia, Saudi J. Biol. Sci. 26 (2018) 1531-1538.

10. V. M. Busch, A. Pereyra-Gonzalez, N. Segatin, P. R. Santagapita, N. Poklar Ulrih, M. P, Buera, Propolis encapsulation by spray drying: Characterization and stability, LWT - Food Sci. Technol. 75 (2017) 227235.

11. M. Sahlan, T. Supardi, Encapsulation of Indonesian propolis by casein micelle, Int. J. Pharma Bio Sci. 4 (2013) 297-305.

12. D. K. Pratami, A. Mun'im, M. Yohda, H. Hermansyah, M. Gozan, Y. R. P. Putri, et al., Total phenolic content and antioxidant activity of spraydried microcapsules propolis from Tetragonula species, in AIP Conf. 
Proc., AIP Publishing, 2085 (2019) 020040.

13. A. N. Diva, D. K. Pratami, A. Wijanarko, H. Hermansyah, M. Sahlan, Effect of ethanolic propolis extract from Tetragonula biroi bees on the growth of human cancer cell lines HeLa and MCF-7, in AIP Conf. Proc., AIP Publishing, 2092 (2019) 30002.

14. S. Silici, A. N. Koc, Comparative study of in vitro methods to analyse the antifungal activity of propolis against yeasts isolated from patients with superficial mycoses, Lett. Appl. Microbiol. 43 (2006) 318-324.

15. P. C. M. Pereira, E. C. Navarro, Challenges and perspectives of Chagas disease: A review, J. Venom. Anim. Toxins Incl. Trop. Dis. 19 (2013).

16. F. S. Marquiafável, A. P. Nascimento, H. da S. Barud, F. MarqueleOliveira, L. A. P. De-Freitas, J. K. Bastos, et al., Development and characterization of a novel standardized propolis dry extract obtained by factorial design with high artepillin C content, J. Pharm. Technol. Drug Res. 4 (2015) 1.

17. F. C. Da Silva, C. R. Da Fonseca, De Alencar, et. al., Assessment of production efficiency, physicochemical properties and storage stability of spray-dried propolis, a natural food additive, using gum Arabic and OSA starch-based carrier systems, Food Bioprod. Process. 91 (2013) 28-36.

18. B. A. S. Machado, R. P. D. Silva, G. D. A. Barreto, S. S. Costa, D. F. Da Silva, H. N. Brandão, et al., Chemical composition and biological activity of extracts obtained by supercritical extraction and ethanolic extraction of brown, green and red propolis derived from different geographic regions in Brazil, PLoS One. 11 (2016) 1-26.

19. N. L. Rosli, H. Roslan, E. A. Omar, N. Mokhtar, N. H. A. Hapit, N.
Asem, Phytochemical analysis and antioxidant activities of Trigona Apicalis propolis extract, in AIP Conf. Proc., AIP Publishing, 2016: p. 20018.

20. C. C. Chang, M. H. Yang, H. M. Wen, Estimation of total flavonoid content in propolis by two complementary colorimetric methods, J. Food Drug Anal. 10 (2002) 178-182.

21. W. Siheri, T. Zhang, G. U. Ebiloma, M. Biddau, N. Woods, M. Y. Hussain, et.al., Chemical and antimicrobial profiling of propolis from different regions within Libya, PLoS One. 11 (2016) 1-16.

22. R. Onbas, A. Kazan, A. Nalbantsoy, O. Yesil-Celiktas, Cytotoxic, and nitric oxide inhibition activities of propolis extract along with microencapsulation by complex coacervation, Plant Foods Hum. Nutr. 71 (2016) 286-293.

23. N. V. N. Jyothi, P. M. Prasanna, S. N. Sakarkar, K. S. Prabha, P. S. Ramaiah, G. Y. Srawan, Microencapsulation techniques, factors influencing encapsulation efficiency, J. Microencapsul. 27 (2010) 187197.

24. D. K. Pratami, A. Mun'im, H. Hermansyah, M. Gozan, M. Sahlan, Microencapsulation optimization of propolis ethanolic extract from Tetragonula spp using response surface methodology, Int. J. App. Pharm. $12(2020) 1$.

25. P. C. T. Hannan, Guidelines and recommendations for antimicrobial minimum inhibitory concentration (MIC) testing against veterinary mycoplasma species, Vet. Res. 31 (2000) 373-395. 